\title{
Prevalence of lower urinary tract symptoms (LUTS) among young age medical population
}

\author{
Zalina $\mathrm{N}^{\mathrm{a}}$, Aruku $\mathrm{N}^{\mathrm{b}}$, Azura $\mathrm{N}^{c}$, Shahida $\mathrm{N}^{\mathrm{c}}$, Akhmarina $\mathrm{N}^{\mathrm{c}}$, Dian $\mathrm{F}^{\mathrm{c}}$ \\ a Urogynaecology \& Pelvic Reconstructive Unit, Department of Obstetrics \& Gynecology, Kulliyyah of Medi- \\ cine, International Islamic University Malaysi \\ b Women Pelvic Health Unit, Department of Obstetrics \& Gynecology, Hospital Ipoh, Perak, Malaysia \\ c Royal College Medicine of Perak, Ipoh, Perak
}

\section{ABSTRACT}

Introduction: Frequency of lower urinary tract symptoms (LUTS) in young age women is not well studied. It is said to be common among female elderly and multiparous population. The aim of this study is to obtain the prevalence of LUTS among nulliparous students in relation to their personal hygiene. Materials and methods: This is a prospective cross-sectional study conducted among 200 nulliparous medical and nursing students aged between 18-28 years using standardized questionnaires. Urine samples were also collected from students to detect urinary tract infections. Results: The complete data sets of 146 students were analyzed. All of them were nulliparous, single and not sexually active. The prevalence of LUTS was $52.7 \%$ consist of over-active bladder, urinary incontinence (UI) and voiding difficulty respectively (51.3\%, 34.9\% and $45.2 \%)$. The most common type of UI was stress urinary incontinence which was $21.9 \%$ followed by $11.6 \%$ of urgency incontinence. Conclusion: The prevalence of LUTS among young age population is high at $52.7 \%$. Public awareness regarding LUTS and availability of treatment is needed.

KEYWORDS: urination disorders, stress urinary incontinence, urinary tract infection, urge urinary incontinence, young adult.

\section{INTRODUCTION}

Lower urinary tract problems are common and distressing among females. ${ }^{1}$ Lower urinary tract symptoms (LUTS) include incontinence (stress urinary incontinence (SUI), urgency incontinence (UUI) and mixed urinary incontinence), over-active bladder $(\mathrm{OAB})$, urinary storage and voiding problems. The symptoms are overlapping and urinary tract infection (UTI) needs to be excluded. LUTS is often attributed to aging and associated with age-related changes such as decreased bladder capacity or incomplete bladder emptying and loss of estrogen. ${ }^{2}$ It was found that $\mathrm{UI}$ to be a common health problem among women even in younger age group. It is associated with poor self-esteem, impaired quality of life, social isolation, and depression. ${ }^{3} \mathrm{UI}$ comprises $85 \%-90 \%$ of all cases in women and ranges from $14.7-52.0 \%$ in healthy young age group. ${ }^{4,5,6}$

Several studies have explored the relationship between $\mathrm{UI}$ and specific variables, some of which suggest causal links between physiological changes and

\section{Corresponding author;}

Dr. Zalina Nusee

Urogynaecology \& Pelvic reconstructive Unit, Department of Obstetrics \& Gynecology

Kulliyyyah of Medicine, International Islamic

University Malaysia

Jalan Hospital, Kuantan, Pahang

Tel: +60199880506

E-mail:drzalina@iiu.edu.my incontinence. Incontinence in women is perhaps most often attributed to the effects of childbearing, ageing and hysterectomy. ${ }^{7}$ Women who have urinary incontinence have an increased risk for UTI and experience increased incontinence during an acute episode. ${ }^{8} \mathrm{Be}$ cause of the paucity of epidemiological data on young age group, we aimed at evaluating the prevalence of and risk factors for LUTS in a female population with a special focus on younger age group, using a standardized questionnaire.

\section{MATERIALS AND METHODS}

This is a cross-sectional study conducted between May 2006 and June 2006. The students who were listed in the Royal College Medicine of Perak (RCMP) and the Nursing College registration book were invited to participate. Total of 200 medical and nursing students were recruited. All were nulliparous, aged between 18-29 years with or without bladder and urinary problems. The participation in this study was voluntary and subjects were free to withdraw at any time.

Subjects were interviewed using a self answered questionnaires consisting of demographic data, modified questionnaire pertaining to urinary incontinence and bladder symptoms (Table I) and assessment on personnel hygiene (Table II). Before distributing the questionnaires, the purpose of the study and contents of the questionnaires were explained to the students. Subjects were consented and confidentiality was ensured by using anonymous questionnaire. Exclusion criteria include all male students, subjects who refused to take part in the study and cases with incomplete information. 
Table I. Questionnaires on bladder and urinary problems

1. In total, how many times do you go to the toilet in a 24-hour period?

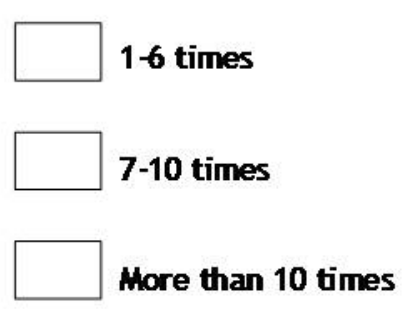

2. How often do you go to the toilet during the day?

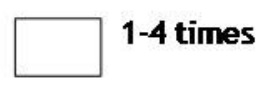

$\square$ More than 8 times

$\square$ 5-8 times

3. How often do you wake up to go to the toilet during the night?

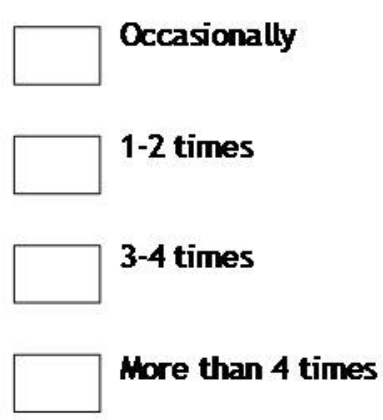

4. Do you feel a strong and sudden urge to urinate?
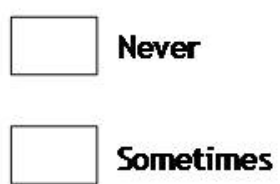

5. Does urine leak before you can get to the toilet?

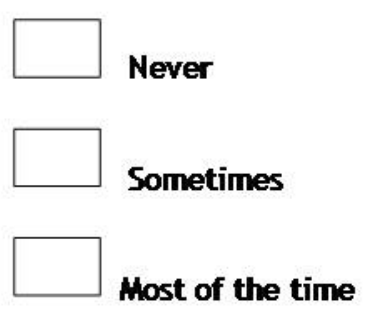

6. Do you leak urine when you laugh, sneeze, cough, jump or run?

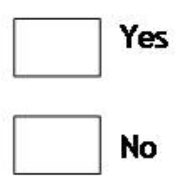

7. Do you leak urine when you are asleep?

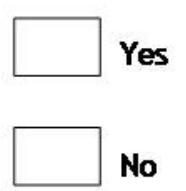

8. Do you have to wear any protections (eg. pads) because of your leakage problems?

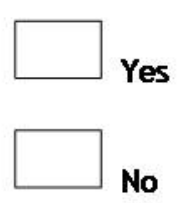

9. Do ou have pain when you urinate?

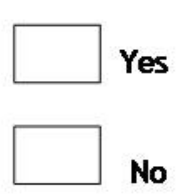
Most of the time 
10. Do you have to strain to urinate?

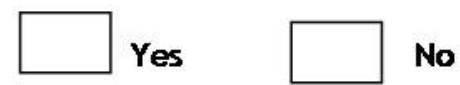

11. Is there a delay before you can start urinate?<smiles></smiles><smiles></smiles>

12. Have you experienced incomplete urinary bladder emptying?<smiles>[Mg][Mg]</smiles><smiles></smiles>

No

13. How often do you take beverages containing caffeine (eg-coffee, tea)?
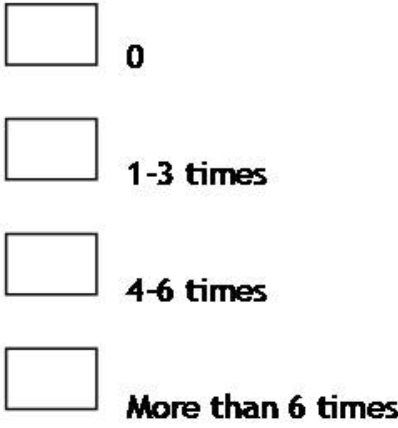

15. Do you smoke?<smiles>C[As]1CCC1</smiles>

If yes how many cigarette do you smoke per day?

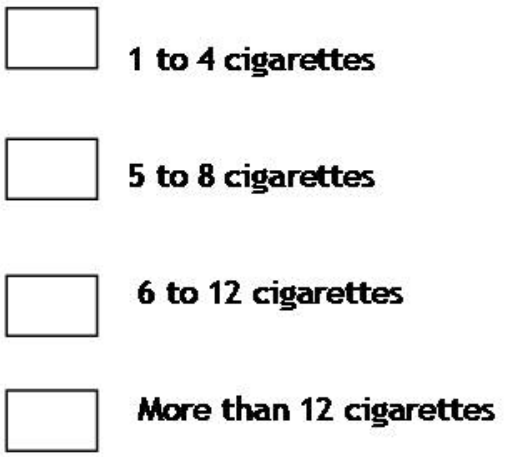

14. Do you drink?

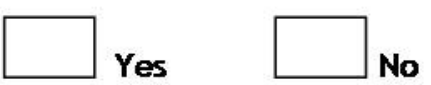

If yes, how many glasses do you drink per day?

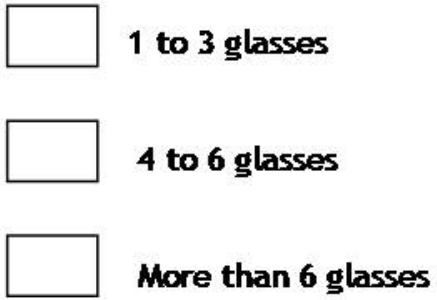

If you have urinary problem, please fill up this part. If not, please go to the next section. For following questions please use this scale;
0 - Not at all
1 - Slightly
2 - Moderately
3 - Greatly

16. Over the past month, do your urinary problems interfere with your physical activity? (eg. swimming, jogging, walking)

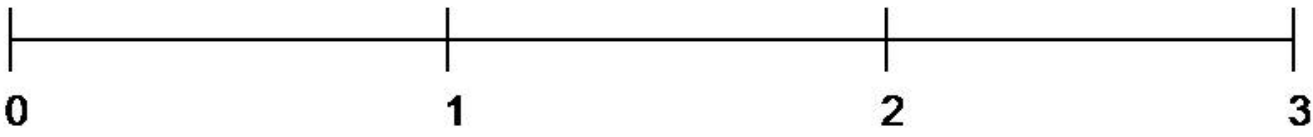

17. Over the past month, do your urinary problems affect your ability to do daily task? (eg. cooking, house cleaning, laundry)

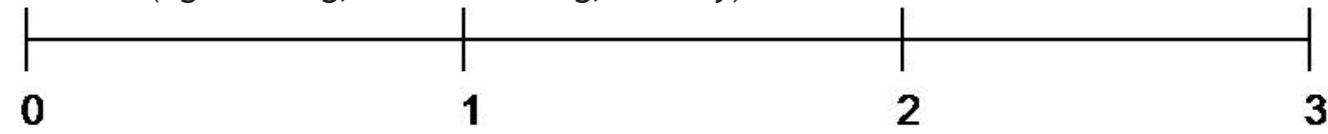

18. Over the past month, do your urinary problems affect your social life?

(eg. meeting friends, watch movies, concert)

\begin{tabular}{l|ll|l|}
\hline & & & \\
0 & 1 & 2 & 3
\end{tabular}


Table II. Questionnaires on personal hygiene

1. How many times do you take your bath each day?
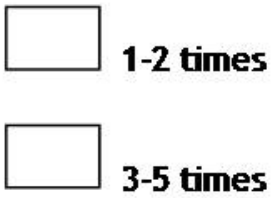

More than 5 times

2. Do you use vaginal douching?

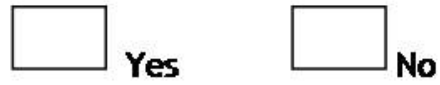

3. Do you wash the inner part of labia majora?
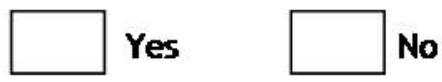

4. Do you dry yourself after each urination?

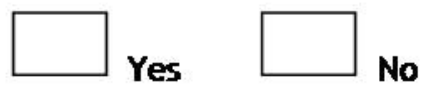

If yes, what do you use to dry yourself with?

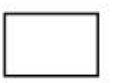

Disposable towel

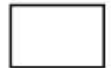

Non-Disposable towel

5. How many times a day do you change your underwear?

No change required

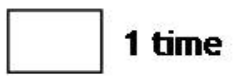

2-3 times

4-5 times

More than 5 times
6. What type of underwear do you usually wear?
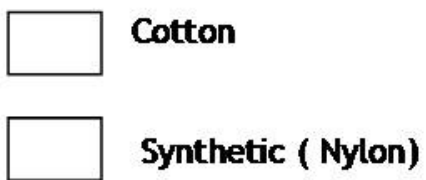

7. Do you wash your underwear separately from your other clothes?

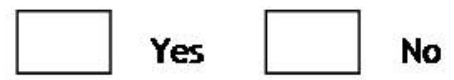

8. Do you wash your underwear with
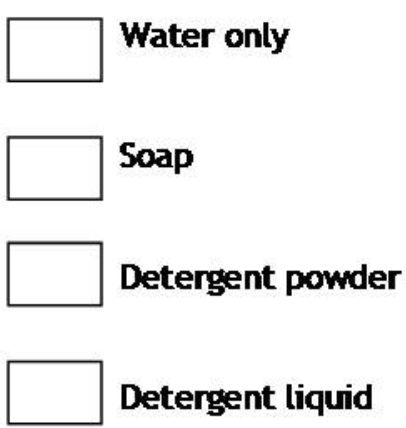

9. Do you wear panty liners / mini pads?

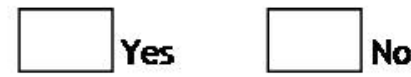

If yes, how frequent do you

change your panty liners?

No change required

1 time

2-3 times

4-5 times

More than 5 times 
10. Do you dry your underwear under the sun?

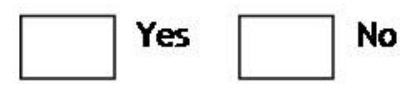

11. Do you wash your hand during this condition?

- After using the toilet

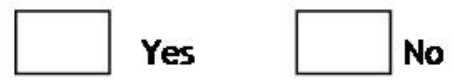

- Before making or eating food

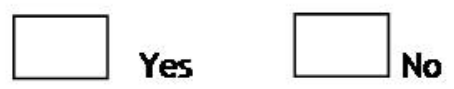

- After handling dogs or other animals

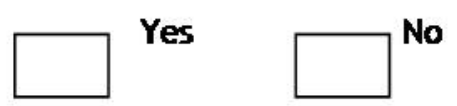

12. How many times on average you change your pad during menstruation?

$\square$ No change required

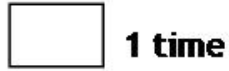

time

2-3 times

4-5 times

More than 5 times
13. After defecation, how do you wash and wipe your rectum and vagina?

From back to front

From front to back

14. Are you a sexually active woman?

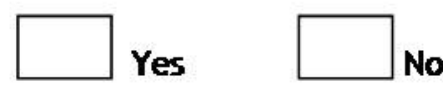

If yes, do you wash your rectum and vagina after sexual intercourse?

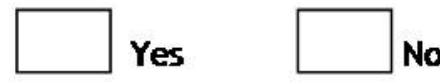


Subjects were required to complete all sections of the questionnaires. The medical students answered English version questionnaires whereas the nursing students used the Malay version. At the end of session, each of the participants was given a urine container for urine sample for verification of UTI. The subjects were instructed to obtain an early morning urine specimen, to clean their perineum, separate the labia and collect mid stream urine. Urine specimens were transported to the laboratory and analyzed within 2 hours after collection to avoid contamination and ensure the accuracy of the result. The urine samples were analyzed using urine dipstick method and microscopic urinalysis.

\section{Definitions}

For the purpose of this study the following definitions were used: (1) UTI is defined as positive symptoms and urine analysis result (presence of more than three leukocytes, red blood cells and nitrite in an uncontaminated specimen). (2) Personal hygiene was further classified as poor (0-13 points), moderate (14-26 points) and good (27-39 points). (3) OAB is defined as 'urgency', with or without UUI usually with increased daytime frequency and nocturia. (4) Urinary urgency is 'the complaint of a sudden compelling desire to pass urine which is difficult to defer' and UUI is 'the complaint of involuntary leakage accompanied by or immediately preceded by urgency'. (5) SUI is involuntary leakage on effort or exertion or on sneezing or coughing. ${ }^{9}$

\section{Statistical test}

SPSS software (version 12, Chicago, Illinois, USA) was used for statistical analysis for both quantitative and qualitative data. Independent t-test was used to compare quantitative with qualitative data. Analytical tests used were Pearson's test to correlate between two quantitative variables and Chi-square test to compare two qualitative variables considering a significant level of $p<0.05$.

\section{RESULTS}

The complete data sets of 146 students were analyzed. The data were obtained from 55 students in medical course and 91 students in nursing course. All of the students were nulliparous, single and not sexually active. The mean age was 21.4 years (range 18-29) and means BMI was 21.42. The majority of students $(89.7 \%)$ were Malay (Table III).

LUTS symptoms were found in 77 subjects $(52.7 \%)$. Majority of the participants 75 (50.7\%) experience urgency and $2.7 \%$ had frequency and nocturia which can be classified as OAB symptoms (table IV). Other major symptoms include voiding dysfunction and UI respectively (45.2\%, 34.9\%). Eleven students (7.6\%) had significant history related to LUTS including history of taking medicines for overactive bladder symptoms (e.g. Ditropan and Tofranil), surgical history (e.g. incontinence surgery) and past experience of bladder problem. Only 3 students $(2.1 \%)$ with the
Table III: Demographic data

\begin{tabular}{|c|c|c|}
\hline Demographic data & $\begin{array}{c}\text { Case } \\
(n=146)\end{array}$ & Frequency (\%) \\
\hline \multicolumn{3}{|l|}{ Age(years): } \\
\hline $18-20$ & 34 & 23.3 \\
\hline $21-23$ & 97 & 66.4 \\
\hline $24-26$ & 13 & 8.9 \\
\hline 27- 29 & 2 & 1.4 \\
\hline \multicolumn{3}{|l|}{ Race: } \\
\hline Malay & 131 & 89.7 \\
\hline Chinese & 4 & 2.7 \\
\hline Indian & 10 & 6.8 \\
\hline Others & 1 & 0.7 \\
\hline \multicolumn{3}{|l|}{$B W:$} \\
\hline$<18.5$ & 31 & 21.2 \\
\hline $18.5-24.9$ & 87 & 59.6 \\
\hline 25- 29.9 & 25 & 17.1 \\
\hline$>30$ & 3 & 2.1 \\
\hline On medications & 2 & 1.4 \\
\hline Surgical History & 3 & 2.1 \\
\hline $\begin{array}{l}\text { Previous history of } \\
\text { UT }\end{array}$ & 6 & 4.1 \\
\hline
\end{tabular}

Table IV: Clinical Presentation of lower urinary tract symptoms

\begin{tabular}{lcc}
\hline Symptoms & Frequency (n=77) Percentage (\%) \\
$\begin{array}{l}\text { Day frequency } \\
\text { (> 8 times) }\end{array}$ & 2 & 1.4 \\
$\begin{array}{l}\text { Night } \\
\text { frequency } \\
\text { Inocturia (> } \\
\text { times) }\end{array}$ & 2 & 1.4 \\
$\begin{array}{l}\text { Urgency } \\
\text { Urgency } \\
\text { incontinence }\end{array}$ & 75 & 50.7 \\
$\begin{array}{l}\text { Stress } \\
\text { incontinence }\end{array}$ & 17 & 11.6 \\
$\begin{array}{l}\text { Bed wetting } \\
\begin{array}{l}\text { Incomplete } \\
\text { emptying }\end{array}\end{array}$ & 4 & 23.3 \\
Straining & 60 & 2.7 \\
\hline
\end{tabular}

*Subjects can have more than one symptom. 
above history continued to have problems with either incontinence or urinary tract infection. Students without the history of LUTS had a greater percentage at $28.8 \%$ (42 students) for having bladder and urinary problems compared to those with positive past history $(p=0.099)$.

Of all the 146 students involved, 11\% (16/146) had positive urinalysis that potentially indicated urinary tract infections. Only $28 \%$ were symptomatic which include lower abdominal pain (15.1\%), oliguria (11.6\%) and dysuria (1.4\%). None of the student reported haematuria. The majority of these students presented with frequent vaginal discharge (72\%) and $2.7 \%(4 / 146)$ had yellow-greenish type of vaginal discharge.

Twenty two students $(15.1 \%)$ revealed good hygiene, 124 (84.9\%) were moderate and none of them found to have poor hygiene. The majority potential UTI $(13 / 16)$ were in the moderate group hygiene $(p$ $=0.664)$ compared to 3 in the good hygiene group $(p=$ 0.600 ) which was statistically not significant. There were no statistically significant correlation between $\mathrm{BMI}$ and age with risk of UI and UTI.

\section{DISCUSSION}

LUTS is proven not only attributed to elderly, multiparity and sexually active group population but also in young age, nulliparous and those who are not sexually active. We reported a high prevalence of LUTS at $52.7 \%$ which is consistent with other studies. ${ }^{1,10,11} \mathrm{We}$ diagnosed $50.7 \%$ subjects with $O A B$ based on symptoms. $O A B$ is a broad spectrum of symptoms, which are usually overlapping between SUI, UI, mixed incontinence and voiding dysfunction. The single most important symptom for $O A B$ is urgency. Urodynamic test is the objective confirmatory tool to differentiate the above diagnoses.

There is distinct lack of consensus relating to the use of urodynamic assessment in the interpretation of voiding dysfunction in women. There are no universally accepted nomograms for women with outflow obstruction. Sander and colleagues prospectively looked at whether a 'minimally' urodynamic evaluation including flow rate and post void residual urine determination was helpful in identifying bladder emptying problems.12 Out of 408 incontinence women, $43 \%$ complained of symptoms of incomplete bladder emptying, but only $6 \%$ of patients were found to have elevated PVR urine $(>149 \mathrm{ml})$. Furthermore, only $1.5 \%$ of patients had clinically significant consequences arising from the abnormalities found by this test. They concluded that in a primary-care setting, health care providers could safely assess women with LUTS without these particular urodynamic studies. ${ }^{12}$

Women have far less voiding dysfunction compared to men. Therefore no questionnaires on the subject of voiding disorders in women have been adequately validated. In women, voiding dysfunction encompasses a heterogeneous group of patients who have difficulty emptying their bladder, whether due to an inability of the detrusor to contract effectively (in the case of flaccid bladder), bladder outlet obstruction, detrusorsphincter-dyssynergia, or a combination of these. For the evaluation of LUTS in female who do not have urinary incontinence symptoms, the International Incontinence Society had proposed the use of International Consultation on Incontinence Questionnaire (ICIQ)-FLUTS. ${ }^{13}$ A modified questionnaire (Table I) was used in our study to cater our target population with urinary incontinence.

SUI remains the predominant type of incontinence (23.3\%) as shown by others which ranged between 14.7 - 52.0\%.5,6 In a study of 4211 healthy nulliparous student nurses (17-25years), Wolin et al. found some degree of stress incontinence in 51\% and daily problem with urine leakage in 16\%. Similarly, Nemir and Middleton reported that of 1327 nulliparous female college students, $52 \%$ had stress incontinence, although only $5 \%$ had urine loss on regular basis. ${ }^{10,11}$

There appears to be epidemiological support for the role of obesity in incontinence. Incontinence has been associated with higher body mass index and greater weight. In one study, a significant relationship was found between UI and body mass index. 6 Women with regular incontinence have the highest body mass index and those without incontinence have the lowest body mass index. A link between body mass index and incontinence supports the concept that weight gain may increase the susceptibility to incontinence and suggests that weight loss may decrease incontinence. However we did not find such a correlation in our study subjects.

Most women with urinary incontinence can be treated by simple interventions. ${ }^{14}$ Nevertheless, many incontinent women suffer in silence. The usual reasons for not seeking help are embarrassment, believing that incontinence is a normal part of ageing and that nothing can be done and fear of surgery. ${ }^{15}$ They may be unaware of the available treatment. There is an obvious need for educating the public about incontinence. ${ }^{3,15}$ The same situation applies to our population as most of the symptomatic subjects did not sought medical treatment.

Symptoms of cystitis are the main key for diagnosis of uncomplicated UTI in young female population. ${ }^{16}$ Our subjects showed $11 \%$ of potentially indicated UTI without obvious classical symptoms. Vaginal discharge was the main complaint (72\%) which could contribute to pyuria. It is important to consider the diagnosis of vaginitis (trichomoniasis or candidiasis) or urethritis (Neisseria gonorrhoeae or Chlamydophila trachomatis) when evaluating female patients who have urinary tract complaints.

Nearly $50 \%$ of female patients seen in the emergency department with symptoms of cystitis were found to have sexually transmitted disease. ${ }^{17}$ Many diseases of the urinary tract produce significant pyuria without 
bacteriuria. These include staghorn calculi, tuberculosis, and infections caused by Chlamydia and Mycoplasma spp.

Hydrodynamic factors by flushing out the contaminated urine and practice good personal hygiene has been associated with a reduction in the incidence of UTI. ${ }^{10}$ However Krienger in his data did not support this classic teachings involving increased water intake, direction of wiping, cranberry juice, and voiding promptly after intercourse. ${ }^{18}$ We also did not find correlation between personal hygiene and risk of UTI which is consistent with Krienger's data.

Because urine cultures are expensive, we decided to analyze our urine sample using urine dipstick method and microscopic analysis only. There have been evaluations to find a more cost-effective method of detecting bacteriuria. It is well known that pyuria is not always present in bacteriuria, nor is it specific for bacteriuria. McNair and colleagues reported a 53\% false negative rate with dipstick screening of nitrite and leukocyte esterase in pregnant patients. ${ }^{19}$ Conversely, Hurlbut et al. reported dipstick urinalysis that shows presence of either leukocyte esterase or nitrites is highly predictive of a positive urine culture, whereas absence of both findings markedly reduces the likelihood. ${ }^{14,20}$ A negative dipstick urinalysis is sufficient to rule out UTI in most cases for otherwise healthy women of reproductive age. The use of dipstick urinalysis improves physicians' diagnostic accuracy and can reduce antibiotic prescribing compared with history and physical examination alone. ${ }^{21}$ Given the increased cost and time involved in performing a formal microscopic analysis, the urine dipstick is the screening test of choice in most scenarios to make the diagnosis of UTI. 22

Several problems had occurred in this study which could affect the results. These include small sample size because many students refused to participate in this study. The reasons were; doubtful of the confidentiality of the study, some claimed the questionnaires were too personal, many of them refused to give urine sample and few did not answer the question completely. There could be some dishonesty in answering personal questions. The study was non representative of the population as respondent could be those who have LUT problems who were trying to know more about their problems.

\section{CONCLUSION}

The prevalence of LUTS among young age group female medical population is high at $52.7 \%$, the symptoms mainly of $\mathrm{OAB}$ and voiding dysfunctions. The risk of UTI and UI did not correlate with the personal hygiene, BMI and age. Public awareness regarding LUTS and the availability of treatment is necessary to reduce the problems.

\section{REFERENCES}

1. Takeda M, Araki I, Kamiyama M, et al. Diag nosis and treatment of voiding symptoms. Urology 2003; 62:11-9.

2. Moreno E, Andreu A, Perez T, et al. Relation ship between Escherichia coli strains causing urinary tract infection in women and the dominant faecal flora of the same hosts. Epidemiol Infect 2006; 134(5):1015-23.

3. Fonda D. Promoting continence as a health issue. Eur Urol 1997; 32: 28-32.

4. Moehrer B, Hextall A, Jackson S. Oestrogens for urinary incontinence in women. Cochrane Database Syst Rev 2003; (2):CD001405.

5. Yarnell JW, Voyle GJ, Richards CJ, Ste phenson TP. The prevalence and severity of urinary incontinence in women. J Epidemiol Commun Health 1981; 35:71-4.

6. Burgio KL, Matthews KA, Engel BT. Preva lence, incidence and correlates of urinary incontinence in healthy, middle -aged women. J Urol 1991;146: 1225-9.

7. Mellier G. Dellile MA. Urinary disorder dur ing pregnancy and post-partum. Rev Franc Gynecol Obstet 1990; 85:525-8.

8. Moore EE, Jackson SL, Boyko EJ, et al. Urinary incontinence and urinary tract infection: temporal relationships in postmenopausal women. Obstet Gynecol 2008; 111:317-23.

9. Abrams P, Artibani W, Cardozo L, et al. Re viewing the ICS 2002 terminology report: the ongoing debate. Neurourol Urodyn 2009; 28:287.

10. Wolin L. Stress incontinence in young, healthy nulliparous female subjects. J Urol 1969; 101:545-9.

11. Nemir A, Middleton RP. Stress incontinence in young nulliparous women: statistical study. Am J Obstet Gynecol 1954; 68:1166-8.

12. Sander P. Should measurement of maximum urinary flow rate and residual urine volume be a part of a "minimal care" assessment programme in female incontinence? Scand J Urol Nephrol 2002; 36:124-7.

13. Chapple CR. Questionnaires vs urodynamics in evaluating LUTS: voiding disorders. Nat Clin Pract Urol 2005; 2:555-64.

14. Seim A, Sivertsen B, Eriksen BC, Hunskaar S. Treatment of urinary incontinence in women in general practice: observational study. BMJ 1996; 312:1459-62.

15. Goldstein M, Hawthorne ME, Engeberg S, McDowell BJ, Burgio KL. Urinary inconti nence. Why people do not seek help. J Gerontol Nurs 1992; 18:15-20.

16. Bent S, Nallamothu BK, Simel DL, et al. Does this woman have an acute uncomplicated urinary tract infection? JAMA 2002;287: 2701-10.

17. Berg E, Benson DM, Haraszkiewicz P, Grieb J, McDonald J. High prevalence of sexually transmitted diseases in women with urinary 
infections. Acad Emerg Med 1996; 3:1030-4.

18. Krieger JN. Urinary tract infections: what's new? J Urol 2002; 168:2351-8.

19. MCNair RD, MacDonald SR, Dooley SL, et al. Evaluation of the centrifuged and Gramstained smear, urinalysis, and reagent strip testing to detect symptomatic bacteriuria in obstetric patients. Am J Obstet Gynecol 2000; 182:1076-9.

20. Hurlbut TA, Littenberg B. The diagnostic ac curacy of rapid dipstick tests to predict uri nary tract infection. Am J Clin Pathol 1991; 96:582-8.

21. Sultana RV, Zalstein S, Cameron P, et al. Dipstick urinalysis and the accuracy of the clinical diagnosis of urinary tract infection. $J$ Emerg Med 2001; 20(1):13-9.

22. Lammers RL. Comparison of test characteristics of urine dipstick and uri nalysis at various test cutoff points. Ann Emerg Med 2001; 38:505-12. 